\title{
Effects of Calyculin A on Amylase Release in Streptolysin-O Permeabilized Acinar Cells
}

\author{
Andreas C.C. Wagner, Claus Schäfer\# and John A. Williams
}

Department of Physiology, University of Michigan, Ann Aibor, Michigan 48109

Received November 13, 1992

SUMMARY: The effects of the phosphatase inhibitors calyculin $A$ and okadaic acid on amylase release from streptolysin- $O$ permeabilized rat pancreatic acini were investigated. Both agents induced similar biphasic effects with moderate potentiation of calcium-stimulated amylase release at medium and strong inhibition at higher concentrations. Calyculin $A$ was thirty times more potent than okadaic acid and at $100 \mathrm{nM}$ totally inhibited calcium-induced amylase release while $3 \mu \mathrm{M}$ okadaic acid reduced amylase release by $78 \%$. $100 \mathrm{nM}$ calyculin A also completely inhibited GTPYS-potentiated amylase release and partially inhibited phorbol ester potentiated secretion. The data indicate that inhibition of a serine/threonine phosphatase, probably a type 1 phosphatase, leads to inhibition of calcium-induced amylase release in permeabilized pancreatic acini . (- 1992 Academic Press, Inc.

Regulated enzyme secretion by pancreatic acinar cells is physiologically induced by phospholipase $C$ linked agonists such as cholecystokinin and carbachol. These agonists act on receptors belonging to the large family of seven transmembrane domain receptors which are coupled to heterotrimeric GTP-binding proteins (1). Receptor occupancy releases the alphasubunit of the G-protein which activates phospholipase $C$. Phospholipase $C$ then cleaves phosphatidylinositol-4,5-bisphosphate into inositol 1,4,5 trisphosphate $\left(\mathbb{P}_{3}\right)$ and diacylglycerol $(2,3)$. $\mathbb{P}_{3}$ releases calcium from intracellular stores $(4)$, while diacylglycerol stimulates protein kinase $C(5)$. Calcium then can regulate several protein kinases and phosphatases present in acinar cells. Considerable evidence exists that changes in the phosphorylation of phosphoproteins are important for the regulation of secretion. Changes in the phosphorylation of several proteins in response to secretory agonists have been demonstrated in rodent pancreatic acinar cells $(6,7,8)$.

In order to gain more insight into the later steps of stimulus-secretion coupling we have developed a system of permeabilized acini using the bacterial pore forming toxin streptolysin-0 $(9,10)$. Similar systems have also been applied by others to a variety of cell types $(11,12)$. The

\# Current address: Abteilung für Gastroenterologie, Phillips Universităt Marburg, Baldingerstr. W3550 Marburg. 
permeabilization allows introduction of compounds such as ions or peptides through pores in the plasma membrane into functionally intact cells in order to study their effects on secretion. Thus the early steps in stimulus-secretion coupling can be bypassed and the actions of intracellular messengers studied directly. As in most permeabilized secretory cells, digestive enzyme secretion by permeabilized rodent pancreatic acini is induced by calcium (9-11).

We have previously shown that inhibition of phosphatase activity by $3 \mu \mathrm{M}$ okadaic acid inhibits hormone-induced amylase release in intact acini and calcium-induced secretion in permeabilized acini (13). Okadaic acid inhibits purified serine/threonine phosphatases 2A, 1 and $2 \mathrm{~B}$ with an $\mathrm{ID}_{50}$ of $1.5 \mathrm{nM}, 200 \mathrm{nM}$ and $4.5 \mu \mathrm{M}$ respectively $(14,15)$. Therefore these results indicated an effect of okadaic acid most likely on phosphatase type1 or $2 \mathrm{~B}$. In the present study we investigated the effects of a different phosphatase inhibitor, calyculin $A$ on amylase release by streptolysin-O permeabilized rat pancreatic acini. Although its structure is distinct from okadaic acid, calyculin $A$ inhibits serine/threonine phosphatase type $2 A$ with similar potency as does okadaic acid but is 50 to 100 times more potent inhibitor of phosphatase type1. Neither agent inhibits phosphotyrosine phosphatase activity $(16,17)$.

\section{MATERIAL AND METHODS}

Chemicals: Streptolysin-O was purchased from Welicome Diagnostics (Greenville, NC); Calyculin A and okadaic acid from LC Services (Woburn, MA); chromatographically purified collagenase from Worthington Biochemical (Freehold, NJ); bovine serum albumin (fraction V) from ICN ImmunoBiologicals (Lisle, IL) and minimal essential amino acids from GIBCO (Grand Island, NY). 12-0-tetradecanoylphorbol-13-acetate (TPA) and all other chemicals were obtained from Sigma Chemical (St. Louis, MO).

Preparation of pancreatic acini: Acini were prepared as previously described (6). Briefly, pancreata from white male Sprague Dawley rats were digested with purified collagenase and dispersed by pipetting through polypropylene pipettes of decreasing orifice, followed by filtration through a $150 \mu \mathrm{m}$ nytex screen. Acini were purified by centrifugation through $4 \%$ bovine serum albumin ( $w$ t/vol) and then preincubated for $30 \mathrm{~min}$ at $37^{\circ} \mathrm{C}$ in $\mathrm{N}-2$-hydroxyethyl-piperazine- $\mathrm{N}-2-$ ethane-sulfonic acid (HEPES)-buffered Ringer solution (HR), pH 7.4, supplemented with $11.1 \mathrm{mM}$ glucose, minimal Eagle's medium amino acids, $5 \mathrm{mg} / \mathrm{ml}$ bovine serum albumin, and $0.1 \mathrm{mg} / \mathrm{ml}$ soybean trypsin inhibitor. Buffers were gassed with $100 \% \mathrm{O}_{2}$. As preliminary experiments had shown that calyculin A and okadaic acid are much more potent in inhibiting amylase release when acini are pretreated for 30 min before stimulation, both agents were present during this preincubation in different concentrations according to the experimental design.

Permeabilization: After preincubation with the indicated amounts of phosphatase inhibitors, acini were pelleted and resuspended in piperazine-N,N'-bis(2-ethanesulfonicacid) (PIPES)buffered potassium glutamate solution containing $20 \mathrm{mM}$ PIPES (potassium salt, pH 7.0), $140 \mathrm{mM}$ potassium glutamate, $1 \mathrm{mg} / \mathrm{ml}$ bovine serum albumin (BSA) and $0.1 \mathrm{mg} / \mathrm{ml}$ soybean trypsin inhibitor. $0.5 \mathrm{ml}$ of acinar suspension was then added to $0.5 \mathrm{ml}$ of the same solution containing phosphatase inhibitors, SLO, EGTA, and MgATP to yield final concentrations of $0.5 \mathrm{IU} / \mathrm{m} / \mathrm{SLO}, 5$ mM EGTA, $1 \mathrm{mM}$ MgATP and the indicated concentrations of calyculin $A$ and okadaic acid. The amount of $\mathrm{Ca}^{2+}$ and $\mathrm{Mg}^{2+}$ to be added to give final concentrations of $1 \mathrm{mM}$ free $\mathrm{Mg}^{2+}$ and specified concentrations of free $\mathrm{Ca}^{2+}$ were calculated using a computer program as described earlier (6). Permeabilized acini were incubated for $20 \mathrm{~min}$ at $30^{\circ} \mathrm{C}$.

Amylase assay: After incubation samples were centrifuged for $10 \mathrm{sec}$ in an Eppendorf microcentrifuge. Amylase was determined in the supernatant using procion yellow starch as substrate (18). At the beginning of the incubation period a $1 \mathrm{ml}$ aliquot of acinar suspension was centrifuged and amylase determined in the supernatant. This time 0 value was subtracted from the values obtained after incubation. The pellets were resuspended in water and sonicated in order to 
determine total acinar amylase content. Amylase release during incubation was expressed as percentage of the total amylase content at the beginning of the incubation.

\section{RESULTS}

Effects of calyculin $A$ on amylase release in permeabilized acini: Calyculin A at a concentration of $100 \mathrm{nM}$ inhibited amylase release induced with a maximal dose of tree calcium (1 $1 \mathrm{M})$. Basal release was unaffected (Fig 1). It is interesting to note, however, that at $30 \mathrm{nM}$ calyculin $A$ there was no inhibition but rather a potentiation of calcium-induced secretion. Lower concentrations of Calyculin A had no effect on secretion. When okadaic acid was used, a similar concentration dependent biphasic curve was observed but the dose response was shifted to the right when compared to the effects of calyculin A. Thus calyculin A is 30 times more potent than okadaic acid in its effects on amylase release. In contrast to okadaic acid, calyculin A also inhibited amylase release completely while inhibition with okadaic acid was only $78 \%$. Okadaic acid at concentrations above $3 \mu \mathrm{M}$ increases basal release (data not shown) which makes interpretation of its effects at these doses difficult. Both agents exhibited their full effects only after 30 min preincubation before permeabilization and stimulation of secretion with $\mathrm{Ca}^{2+}$. Without any preincubation there was little effect on amylase release (data not shown).

Opposite effects of calyculin $A$ at 30 and $100 \mathrm{nM}$ on calcium-induced amylase release: We then investigated the effect of $100 \mathrm{nM}$ and $30 \mathrm{nM}$ calyculin $A$ on a full calcium dose response of amylase release (Fig 2). Secretion was stimulated by $\mathrm{Ca}^{2+}$ in a dose-dependent fashion; maximal release was observed at $1 \mu \mathrm{M}$ while secretion was inhibited at higher concentrations of free calcium. After

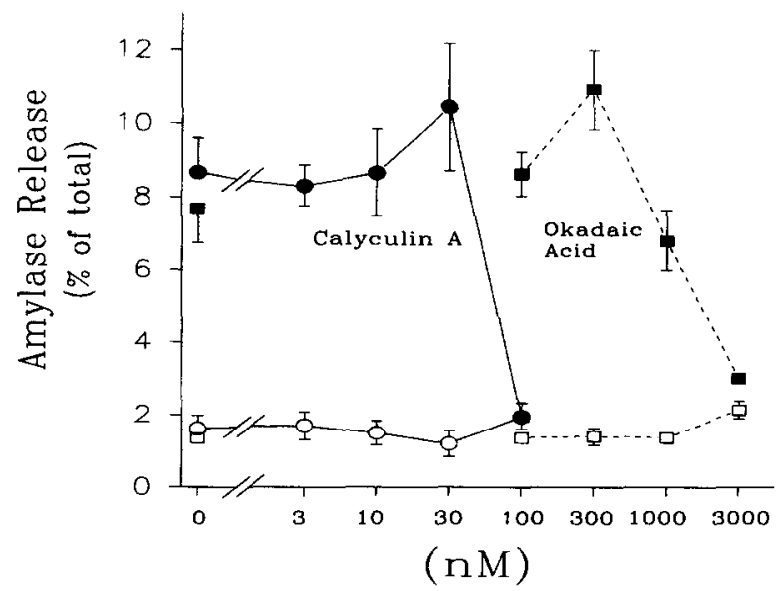

Figure 1. Concentration dependence of calyculin $\mathrm{A}$ and okadaic acid action on calcium stimulated amylase release trom permeabilized acini. Rat pancreatic acini were preincubated for $\mathbf{3 0}$ min with the indicated concentration of calyculin $A(0,0)$ or okadaic acid $(\square, \square)$. Acini were then permeabilized with $0.5 \mathrm{U} / \mathrm{ml}$ streptolysin- 0 and incubated with either $<10^{-9}(0,0)$ or $10^{-6}(,, \mathrm{M}) \mathrm{M}$ calcium for $20 \mathrm{~min}$ at $30^{\circ} \mathrm{C}$. Amylase released after permeabilization was determined and expressed as \% of total amylase content. Values are means \pm standard errors of four (calyculin A) or three (okadaic acid) different experiments in each of which each point was determined in duplicate. 


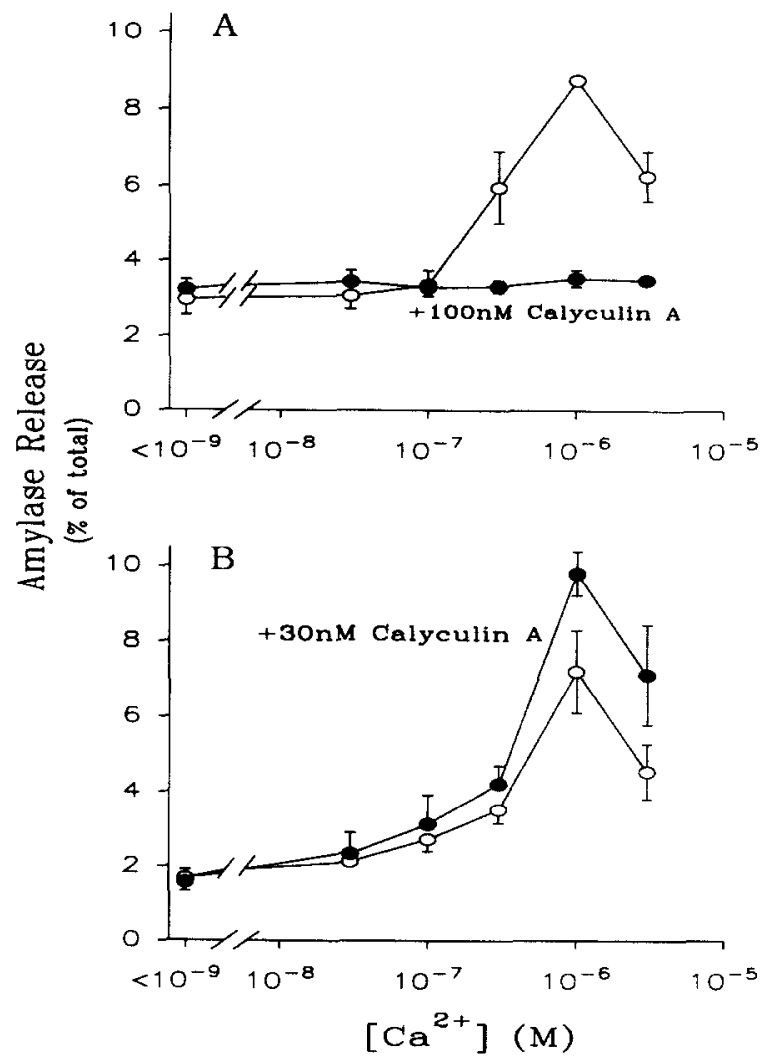

Figure 2. Divergent effects of different concentrations of calyculin A. Experimental conditions were as in figure 1 but the concentration of calcium was varied. Values are means \pm standard errors of 3 experiments in each of which each point was determined in duplicate.

30 min preincubation $100 \mathrm{nM}$ calyculin A completely inhibited calcium-induced secretion at all concentrations of calcium (Fig 2A). The bottom panel shows that $30 \mathrm{nM}$ calyculin A did not inhibit secretion but increased maximal amylase release by $26 \%$ (Fig $2 \mathrm{~B}$ ). This potentiation only occured at maximal doses of calcium but did not lead to a left shift of the calcium dose response curve. Basal release was not affected by either dose of calyculin A although the basal release in the set of experiments with or without $100 \mathrm{nM}$ calyculin A was higher than in the set of experiments with 30 nM calyculin.

Calyculin A totally inhibits GTPYS-potentiated and partially inhibits TPA-potentiated secretion: GTPYS and phorbol esters such as TPA have been shown to potentiate calcium-stimulated amylase release by permeabilized acini $(10,11)$. We investigated the effects of calyculin $A$ on phorbol ester and GTPyS-potentiated secretion (Fig 3). Potentiation by both agents occured in a dose dependent manner with maximally effective doses of $30 \mu \mathrm{M}$ GTP $\gamma$ s and $1 \mu \mathrm{M}$ TPA respectively. The potentiation was strongest at $300 \mathrm{nM}$ calcium where release was increased by 80-100\% compared to calcium alone, while maximal release at $1 \mathrm{mM}$ calcium was increased by only $30-40 \%$ (data not shown). Therefore the calcium concentration used for these experiments was $300 \mathrm{nM}$. Calyculin A completely inhibited the effect of GTPYS plus $300 \mathrm{nM}$ calcium but only partially blocked the effect of TPA plus calcium (Fig 3). 


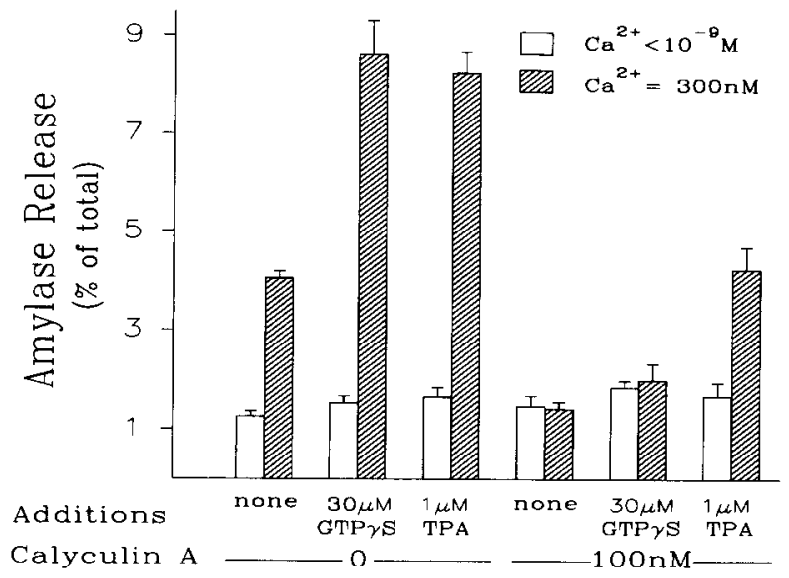

Figure 3. Effect of calyculin A on GTP $\gamma$ and TPA potentiated amylase release. Values are means \pm standard errors of three different experiments in each of which each point was determined in duplicate.

\section{DISCUSSION}

In this study we have used the phosphatase inhibitors calyculin A and okadaic acid to investigate their effects on $\mathrm{Ca}^{2+-i n d u c e d}$ amylase release in permeabilized rat pancreatic acini. Both agents are believed to be specific for serine/threonine phosphatases and have not been found to have an effect on tyrosine phosphatases or other kinases and phosphatases (14-17).

Calyculin $\mathrm{A}$ at $100 \mathrm{nM}$ totally inhibited secretion while okadaic acid at $3 \mu \mathrm{M}$ inhibited amylase release by $78 \%$. It is interesting to note that both agents had a biphasic effect with moderate potentiation of calcium-induced release at medium doses ( $30 \mathrm{nM}$ and $300 \mathrm{nM}$ respectively). The reasons for this biphasic response are not clear but it indicates that these compounds have multiple effects on different phosphoproteins. Although there is no direct evidence which type of phosphatase is inhibited by calyculin A and okadaic acid, the higher potency of calyculin A suggests that inhibition of a phosphatase type 1 is the likely mechanism of action (15). However, to our knowledge calyculin A has not been tested for inhibition of the calcium dependent phosphatase $2 B$ while okadaic acid inhibits this enzyme at micromolar concentrations (14).

One explanation for the inhibition of amylase release by both calyculin $A$ and okadaic acid is that inhibition of serine/threonine phosphatase activity shifts the steady state of phosphorylation of acinar phosphoproteins towards stronger phosphorylation as we have shown previously (13). This could then lead to inhibition of important steps in stimulus-secretion coupling. The fact that a 30 min preincubation before stimulation of secretion is necessary for both calyculin $A$ and okadaic acid to fully inhibit amylase release supports that assumption. Alternatively, it could be assumed that a serine/threonine phosphatase mediated dephosphorylation plays an important role in stimulus-secretion coupling and that calyculin $A$ and okadaic acid act through inhibition of this dephosphorylation to block secretion. The dephosphorylation of a 20 and $21.5 \mathrm{kDa}$ phosphoprotein has been shown to correlate well with the onset of amylase secretion by mouse pancreatic acini (19). We have recently shown that okadaic acid inhibits hormone-induced amylase release in intact and calcium-induced amylase release in permeabilized rat pancreatic acini. Okadaic acid also strongly increased overall protein phosphorylation and inhibited the CCK-induced 
dephosphorylation of a $19 \mathrm{kDa}$ phosphoprotein (13). If a dephosphorylation is important in stimulus-secretion coupling a calcium dependent phosphatase type $2 \mathrm{~B}$ would seem to be a likely candidate as effector for a regulated dephosphorylation. In paramecium a calmodulin/calcineurin dependent dephosphorylation was shown to be important for secretion (20).

As in other systems calcium dependent amylase release in streptolysin-0 permeabilized acini can be further potentiated by other agents such as GTPYS or phorbol esters $(9,10,21,22)$. In our experiments GTP $\mathcal{S}$ showed an effect on amylase release only together with stimulatory concentrations of $\mathrm{Ca}^{2+}$ while at low free calcium, GTPYS has no effect (Fig 3, ref.10). Similar results have been found by others $(21,24,25)$ although there are reports indicating that GTPYS alone (26) or at a calcium concentration of as low as $10^{-8} \mathrm{M}(11)$ can stimulate amylase release in streptolysin- $O$ permeabilized rat pancreatic acini. The reasons for these differences are unclear. The fact that Calyculin A completely blocks secretion induced by both calcium and GTPYS (Fig 3) indicates that GTP $S$ has its effect on the calcium mediated pathway in stimulus-secretion coupling and does not act independently.

Activation of protein kinase $\mathrm{C}$ with phorbol esters also potentiates calcium-induced amylase release although there is evidence that protein kinase $C$ activation is not required for calcium dependent secretion to occur (22). There is also evidence that the effect of phorbol ester on secretion in acini may not be due to its effects on protein kinase $C$ (27). This might explain why neither calyculin A nor okadaic acid were able to fully inhibit secretion induced by both phorbol ester and calcium.

The present work clearly supports the importance of reversible protein phosphorylation in the regulation of secretion but further work is needed to identify both the phosphatases and the substrate proteins involved. Both calyculin A and okadaic acid will be useful tools in this endeavor.

\section{ACKNOWLEDGMENTS}

This research was supported by NIH grant DK 41122 and the Michigan Gastrointestinal Peptide Digestive Disease Center (DK 34933) both to J.A.W. A.W. was supported by a grant from the DFG (Wa 760/2-1).

\section{REFERENCES}

1) Williams, J.A., Burnham, D.B., Hootman, S.R. Gastrointestinal Physiology Volume III by Forte, J. (ed.) American Physiological Society 419-441, (1989).

2) Meldrum, E., Parker, P.J. and Carozzi, A. (1991) Biochim Biophys. Acta 1092, 49-71.

3) Simon, M.I., Strathmann, M.P. and Gautam, N. (1991) Science 252, 802-808.

4) Streb, H., Irvine, R.F., Berridge, M.J. and Schulz, I. (1983) Nature 306, 67-69.

5) Nishizuka Y. (1984) Nature 308, 693-698.

6) Burnham, D.B. and Williams, J.A. (1982) J. Biol. Chem. 257, $10523-10528$.

7) Freedman, S.D. and Jamieson, J.D. (1982) J. Cell Biol. 95, 903-908.

8) Vandermeers, A., Vandermeers-Piret, M.C., Delange, J.P., Wieland, J. and Christophe, J. (1984) Peptides 5, 359-365.

9) Kitagawa, M., Williams, J.A. and DeLisie, R.C. (1990) Am. J. Physiol. 259, G157-G164.

10) Kitagawa, M., Williams, J.A., DeLisle, R.C. (1991) Biochim. Biophys Acta 1073, 129-135, .

11) Padfield, P.J., Ding T.-G. and Jamieson, J.D. (1991) Biochem. Biophys. Res. Commun. 174, 536-541.

12) Lindau, M. and Gomperts B.D.(1991) Biophys.Biochim.Acta 1071, 429-471. 
13) Wagner A.C.C., Wishart,M. Yule, D.I. and Williams J.A. (1992) Am.J.Physiol.:Cell Physiol, in press.

14) Bialojan, C. and Takai, A. (1988) Biochem. J. 256, 283-290.

15) Cohen, P., Holmes, C.F.B., and Tsukitani, Y. (1990) TIBS 15, 98-102.

16) Ishihara,H., Martin,B.L., Brautigan,D.L., Karaki,H., Ozaki,H., Kato,Y., Fusetani,N., Watabe,S., Hashimoto,K., Uemura,D. and Hartshorne,D.J. (1989) Biochem.Biophys.Res. Commun. 159, 871-877.

17) Sugunama,M., Fujiki,H., Okabe,S., Nishiwaki,S., Brautigan,D., Ingebritsen, T. and Rosner,M.R. (1992) Toxicon 30, 873-878.

18) Jung, D.H. Preparation and application of procion yellow starch for amylase assay. (1980) Clin. Chem. Acta 100, 7.

19) Burnham, D.B., Munowiz, P., Hootmann, S.R., and Williams, J.A., (1986) Biochem. J. 235, 125-131.

20) Moyamezi, M., Lumpert, C.J., Kersken, H., Gras,U., Plattner, H., Krinks, M.H.and Klee, C.B. (1987) J. Cell. Biol. 105,181-189.

21) Stecher, B., Ahnert-Hilger G., Weller,U., Kemmer,T.P. and Gratzl,M. (1992) Biochem. J. 283, 899-904.

22) O'Sullivan, A.J. and Jamieson J.D. (1992), Biochem.J. 285, 597-601

23) Gomperts,B.D.,(1990) Annu.Rev.Physiol. 52, 591-606.

24) Edwardson, J.M., Vickery,C. and Christy, L.J. (1990) Biochem. Biophys. Acta 1053, 32-36.

25) Engling, R., Föhr, K.J., Kemmer, T.P. and Gratzl, M. (1991) Cell Calcium 12, 1-9.

26) Winand J. Delporte, C., Poloczek, P., Cantraine, F., Dehaye, J.-P. and Christophe, J. (1991) Second Messengers And Phosphoproteins 13, 173-186.

27) Pandol, S.J. and Schoeffield, M.S. (1986) J. Biol. Chem. 261, 4438-4444. 